Approaches to improving school attendance: Insights from Australian principals

Martin Mills (1), Angelique Howell* (2), Deborah Lynch (2) and John Dungan (2)

(1) University College London

(2) The University of Queensland

*Corresponding author Angelique Howell: a.howell@uq.edu.au

\begin{abstract}
School absenteeism has been concerning educators in the Global North (including Australia) as research suggests a relationship between school attendance, academic achievement and subsequent life chances. This paper focuses on the perspectives of 50 school leaders in Queensland, Australia about approaches to improving attendance. Strategies reflected the cultural, economic and social diversity of their school communities. In general, quality curricula and pedagogies were considered important, but were not explicitly linked to attendance. This suggests the need for schools to develop strategies to enhance student engagement in meaningful learning through quality curricula and pedagogies within a positive school environment.
\end{abstract}




\section{Approaches to improving school attendance: Insights from Australian principals}

\section{Abstract:}

School absenteeism has been concerning educators in the Global North (including Australia) as research suggests a relationship between school attendance, academic achievement and subsequent life chances. This paper focuses on the perspectives of 50 school leaders in Queensland, Australia about approaches to improving attendance. Strategies reflected the cultural, economic and social diversity of their school communities. In general, quality curricula and pedagogies were considered important, but were not explicitly linked to attendance. This suggests the need for schools to develop strategies to enhance student engagement in meaningful learning through quality curricula and pedagogies within a positive school environment.

Key words: Attendance, school leadership, equity, curriculum, pedagogy

\section{Introduction}

Equity considerations have meant that improving student attendance at school has been a major concern of governments worldwide (Birioukov, 2016; Kearney, 2003). There is a body of literature to suggest that frequent absences from school are linked to poor academic achievement, school drop-out, at-risk behaviours, involvement in the youth justice system, and more limited life opportunities (Birioukov, 2016; Kearney \& Graczyk, 2014; Rocque, Jennings, Piquero, Ozkan, \& Farrington, 2016). Absenteeism has also been discussed in relation to students' personal, cultural, economic, and social circumstances (McGregor \& Mills, 2012; Skattebol \& Hayes, 2016) which may affect students' ability to attend school, and potentially perpetuate cycles of non-attendance into subsequent generations (Reid, 1999). The current research was undertaken to explore strategies used by government primary and secondary schools in Queensland, Australia, to improve school attendance. This paper focuses on school leaders' perspectives about their approaches to improving attendance.

In Australia, all States and Territories have in place legislation outlining the responsibilities of parents and carers in relation to ensuring that their children attend school. In all jurisdictions, young people between the ages of six and 17 years of age are required to either be enrolled at a registered school, registered for home schooling, or participating in an eligible work or study option. Across the country, school leaders manage compliance with legislative requirements in regard to attendance, through data management systems to ensure accurate and daily attendance records are maintained, and apply local processes and support mechanisms to optimise student attendance and re-engage students. The Commonwealth Government's MySchool website which was designed to ensure that all 
Australian schools' data are made publicly available also reports individual schools' absence data. In Queensland, a Parliamentary Committee Report, 'Review of state school attendance rates' identified a lack of high quality research on programs and practices in schools that improved attendance. This research was commissioned as a response to this recommendation to explore strategies used by government schools in order to improve school attendance.

\section{Perspectives and terminology}

Absenteeism is generally defined in terms of 'excused or unexcused absences from school' (Kearney \& Graczyk, 2014, p. 257) with 'unexcused absences' often used interchangeably with 'truancy' in the literature (Birioukov, 2016). However, it has been argued that this simplistic definition not only fails to account for the many causes of absence, it is largely incognisant of the complexity of absenteeism, and can be used to shift the blame for absenteeism onto students; effectively absolving wider society of any responsibility (Reid, 2010).

Research has tended to examine issues relating to absenteeism and individual students, their families or schools from particular discipline perspectives, including psychology, social/criminal justice, health sciences, leadership, ethics, law and psychiatry, as well as education (Birioukov, 2016; Kearney, 2008). However, Kearney (2008) argues that these varying approaches have led to a multiplicity of definitions and use of key terminologies. As a result, these disciplinary literatures utilise terms such as absenteeism, truancy, school refusal, and excused/unexcused absences interchangeably. This in turn has resulted in 'wide discrepancies in how schools define and catalogue absences, creating ambiguity in identifying absentees' (Birioukov, 2016, p. 345). Writing in the UK, Reid (2010, p. 2) argues that this is evidenced in 'statistics on non-attendance [which] are now quantified differently not only in the four UK administrations ... but also in other parts of the world such as France, Portugal, Australia, New Zealand, Canada and different states within the United States'.

Drawing from the work of Driver and Watson (1989) and Steers and Rhodes (1978),

Birioukov (2016) proposes utilising the concepts of 'voluntary' and 'involuntary' absenteeism as 'a more suitable framework for conceptualising absenteeism in academic research' (p. 341). Within this framework, voluntary absenteeism is defined in terms of individual students' motivation to attend school which recognises students' agency in their decision to attend. Involuntary absenteeism conversely refers to the life conditions which can impact upon young people's capacity to attend school. This framework is useful in its capacity to distinguish between students' agency and life circumstances which may inhibit their ability to attend school. However, as argued above, binary frameworks may also inhibit a deeper exploration of this complex issue. 


\section{Contributing factors to absenteeism}

Internationally, the literature indicates that the causes of absenteeism from school are complex and varied. Historically, students have typically been held responsible for their own absences from school, with their parents/carers also blamed for failing to ensure that their children attend school regularly. However, in their research with young people in South Los Angeles who reported 'skipping' school at least once per month, Gase, DeFosset, Perry, and Kuo (2016) found that students attributed their absenteeism primarily to school factors such as curriculum, pedagogy and teachers. Furthermore, schools have been perceived by parents and students as judgmental, unsympathetic to personal circumstances and failing to protect students from bullying (Reid, 2010). Hostile student-teacher relationships, arising from punitive behavior management practices have also been cited as a cause of absenteeism, with students experiencing a sense of injustice, or of not being treated fairly, and personality clashes with particular teachers (Mills \& McGregor, 2014). When surveying students about school environments, Van Eck, Johnson, Bettencourt, and Lindstrom Johnson (2017) also found that students attributed higher rates of chronic absenteeism to negative school climates.

Student perceptions of an irrelevant curriculum have also been found to contribute to absenteeism (Corville-Smith, Ryan, Adams, \& Dalicandro, 1998; Elliott, 1999). In England and Wales, the National Curriculum has been the source of much criticism in this regard. Reid (2010, p. 9) argues, 'Recent studies [in those countries] have suggested that many disaffected pupils have become disenchanted with the content and repetitious nature of the National Curriculum in England and Wales'. In Australia, Mills and McGregor (2014) in their interviews with students who had left the mainstream schooling sector indicated that curriculum and pedagogical practices that did not engage students, along with lack of individual attention, were major factors in their decision to leave mainstream education.

While absenteeism is linked to poor academic achievement (Reid, 2012), it is not clear from the research whether the absenteeism causes the low achievement, the low achievement causes the absenteeism, or the extent to which they are interlinked. Corville-Smith et al. (1998) found that absentee students had lower self-esteem and academic self-concept than students who attended regularly. Other research suggests that punitive responses exacerbate a sense of academic 'failure', which further compounds the problem (Reid, 2012). A range of psychological issues, such as anxiety and depression, have also been associated with 'school refusal' and absenteeism (Kearney, 2008).

Families' socio-economic circumstances, such as experiences of poverty, have also been associated with absenteeism and disengagement from schooling (Kearney, 2008; Marvul, 2012; Zhang, 2004). This may include a lack of transportation to school and inadequate access to resources (Gottfried, 2009; Ham, 2004; Marvul, 2012), insecure parental employment, additional employment commitments for students to supplement the family income (Skattebol et al., 2014), or homelessness (Kearney, 2008; McGregor, Mills, te Riele, 
Baroutsis, \& Hayes, 2017). Stressful events and family circumstances, such as divorce, separation, child maltreatment, conflict and substance abuse, also contribute to chronic absenteeism (Kearney, 2008). Whilst many young mothers seek to complete their schooling, they may find it increasingly difficult to continue, particularly if they lack support (McGregor, et al., 2017; Mills \& McGregor, 2014). There is evidence to suggest that cultural perspectives and differing world views can influence perceptions of formal education, which may also interact with issues such as low income and institutional racism inherent within many education systems (Gillborn, 2008).

\section{Strategies to improve attendance}

The complexity of the phenomenon of absenteeism is recognised within the current literature (Corville-Smith et al., 1998; Marvul, 2012; McIntyre-Bhatty, 2008). In developing strategies to address absenteeism, it is necessary to explore contributing factors as interconnected rather than in isolation. Current strategies include, but are not limited to, developing better relationships with students and the school community, creating a positive school climate, and developing both rewards and sanctions in regards to attendance; all of which are typically accompanied by a systematic monitoring of data.

The literature suggests that respectful and collaborative relationships between schools, students and their parents/carers are critical to improving students' attendance at school and their learning outcomes (Eaton et al., 2008; Povey et al., 2016). Such relationships have been shown to enhance communication and foster a school climate in which staff are viewed as approachable. Outreach activities and home visits, as well as encouraging parents to visit the school for classroom and extra curricula activities supports the development of these relationships (Kearney, 2008; Stone \& Stone, 2011). Research also suggests that strategies to involve culturally and linguistically diverse parents to bridge language and cultural differences include employing interpreters, conducting home visits, promoting cultural inclusivity and responsiveness, and issuing invitations to special events in various languages and including all family members' (Broussard 2003; Garcia-Garcia 2008; Kearney and Bates 2005). In Australia, working closely with local Aboriginal and Torres Strait Islander communities has been shown to support young Indigenous people to connect with schooling (see for example, Baxter \& Meyers, 2016). While principals play a key role in shaping school climate and facilitating school-parent relationships, there is still much to be learned about how principals facilitate parent-school partnerships (Povey et al., 2016) School related factors, such as creating a school climate, which refers to the subjective experience of everyday school life (National School Climate Council, 2007) in which students feel safe, respected and valued; the presence of empathetic teachers (DeSocio et al., 2007); quality curricula and pedagogical practices that that engage students (McGregor et al., 2017); and flexibility in terms of schedules and courses are important for improving attendance, especially for vulnerable young people (Kearney, 2008; Mills \& McGregor, 2014; Reid, 2007). In Australia, as elsewhere, there is a growing reliance on alternative provision to address chronic absenteeism (DeSocio et al., 2007; McGregor et al., 2017; Tate \& 
Greatbatch, 2017). Many schools have developed reward systems to encourage attendance. However this approach has been questioned, with Arthurs, Patterson, and Bentley (2014, p. $865)$ arguing that: 'the use of incentives to lure a student into school belittles the role of a school and its purpose as a place of learning'. Increasingly, schools and school systems around the world have been including students' voices in developing strategies to improve school attendance (Forde, Horgan, Martin, \& Parkes, 2018; Raby, 2014; Robinson, 2011; Robinson \& Taylor, 2013; Taylor \& Robinson, 2009).

In most jurisdictions, monitoring student attendance data is an essential feature of approaches to addressing attendance issues. For example, in Australia, attendance data are frequently used as a starting point to develop programs that address non-attendance (Zubrick, 2014). These programs may include psychological interventions, which 'concentrate primarily on child symptoms ... and circumscribed intervention' (Kearney, 2008 , p. 258). This may involve trying to 'treat' behaviours such as anxiety with various strategies, for example, cognitive therapy, or antidepressant medications. An alternative approach is one which seeks to 'clear the path for learning' (McGregor et al., 2017), where there are attempts to accommodate or ease the difficulties young people face as the result of homelessness, poverty or young parenthood.

Legal sanctions, such as punitive measures to ensure parental and student compliance through legislative processes have rarely been successful (Eastman, Cooney, O'Connor, \& Small, 2007; Reid, 2010; Zhang, 2004). For example, in Queensland, Australia, Dickson and Hutchinson (2010) noted that prosecutions are rarely implemented, and that this approach has had the opposite of its intended effect. These authors highlight the potential problems with punishing parents in order to benefit children, which implies that parental failure is the cause of truancy. The same can be said of withholding welfare payments from parents of young people truanting (See for example, Justman \& Peyton, 2014). In some US jurisdictions, young people can themselves be prosecuted. However, Birioukov (2016) argues that 'criminalizing truancy does not appear to have had positive results, with evidence suggesting that many prosecuted truants displayed higher absence rates following the court proceedings' (p. 345).

Despite the complex and multifaceted nature of absenteeism, the literature has elucidated strategies being adopted to improve attendance. It also highlights the need for further research to explore the approaches of schools that have demonstrated improvements in attendance rates.

\section{Methodology}

This research was designed to develop an understanding of the strategies that schools with improved attendance data were utilising to achieve this outcome. While the project was designed in three stages, this paper focuses on Stage Two. Ethical clearance for the project 
was obtained from the university and permission to conduct research in government schools in Queensland was received from the Department of Education.

The first stage of the project reviewed publicly available and school-level secondary data sets from three distinct data sources: data on government schools in Australia compiled from the Reports of Government Services (ROGS); administrative data provided by the Queensland Department of Education on attendance patterns in all state schools in the State; and results of a survey of Queensland state school leaders from higher and lower attendance schools on strategies that improve attendance. The school-level data additionally provided school-level statistics, such as school-level annual attendance rates and the number of students attending schools each day, proportion of Indigenous students, and socioeconomic status quintile per School. Analysis of these data identified 50 schools which had demonstrated improved student attendance. These included 17 primary and 33 secondary schools in predominantly low SES communities as determined by their Index of Community Socio-Educational Advantage (ICSEA) value ${ }^{1}$ (See Figure 1).

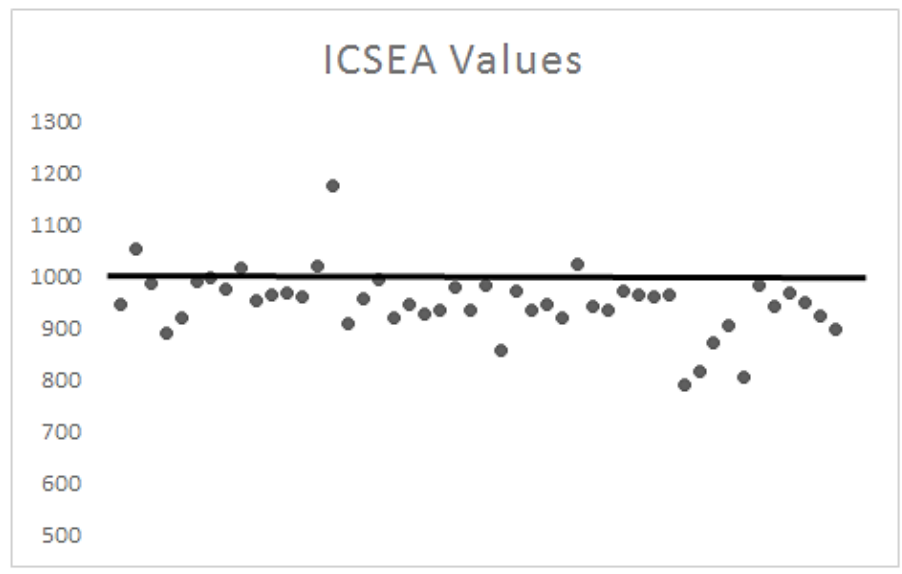

Figure 1. Distribution of ICSEA values of the schools

The schools were located across the seven Queensland Department of Education regions, with 16 metropolitan, 28 regional and 6 remote schools. These schools ranged in size from approximately 80 students in one regional primary school to almost 2600 in one metropolitan secondary school. The percentage of Indigenous students varied widely, from $1 \%$ in a metropolitan school to $69 \%$ in a regional school. Students with a Language Background Other Than English (LBOTE) similarly ranged from $0 \%$ in one regional school, to $50 \%$ in one regional and one metropolitan school.

The second stage of the project, which comprises the focus of this paper, involved telephone interviews with the 50 school principals (or their representatives) from schools selected in Stage One. Interviews lasted for approximately one hour, and sometimes

\footnotetext{
${ }^{1}$ ICSEA is a scale that represents levels of socio-educational advantage and ranges from 500 to represent extreme educational disadvantage to 1300 for very educationally advantaged students. The average ICSEA for Australian schools is 1000 (ACARA, 2011).
} 
included a deputy principal or other senior figure in the school. The interviews sought school leaders' perspectives on the causes of absenteeism, covering a wide range of personal, life and school circumstances, and a broad overview of the strategies used by the schools to improve student attendance. Analysis of these transcripts was thematic; a method for encoding data through identifying patterns and themes within the interview responses (Braun \& Clarke, 2006). Some of these themes were inductively generated from the data, while others were drawn deductively from the review of the literature. The data were coded into the following broad categories: contributors to absenteeism and strategies to improve attendance, which included addressing conditions that prevented student attendance, facilitating conditions to promote school attendance, and the use of sanctions. In Stage three, 10 of the 50 schools were selected to participate in case studies, which will be discussed in a future paper.

\section{Findings}

From the interviews, it was clear that these school leaders were confronting a range of issues in a variety of contexts. There was awareness that strategies that were successful for these schools may not be transferrable to other contexts. Engaging the whole school community through a strategic approach and collective ownership of the aim to improve attendance emerged as an important theme. This was summed up by one school leader: 'It is about identifying a clear, strong strategy and knowing ... what everyone's role is in that and communicating that ... The school has to own it ... we owe it to the students and families in our school environment'.

\section{Contributors to absenteeism}

The interviews revealed perceptions of multiple contributors to absenteeism, many of which were seen to be interrelated, which resonated with findings within the literature. These principals were aware of the life circumstances of some students that impacted on their ability to attend school. For example, one principal emphasised, 'if they don't have a roof over their head or food/clothing, they are not really going to be worried about attendance at school.' This also related to some students who for various reasons had to live independently of their families.

A principal in a regional school referred to changing economic conditions in the area, which he believed impacted on students' motivation to attend school:

We were in the middle of a mining boom ... you had kids ... being offered apprenticeships with the big gas project ... that's all of a sudden dried up ... We have a certain amount of apathy ... in that certain kids ... don't believe that there's going to be a future.

In some of the areas, families were engaged in industries that employed fly in/fly out (FIFO) workers. This lifestyle also seemed to impact upon students, for example: 
Mum or dad or both, will go off and work ... 6 am till $6 \mathrm{pm}$ for four days and have three days off so for those shift days, often the parents are trusting the kids to do the right thing ... leaving them with money ... a well-stocked fridge ... [but] mum and dad aren't around.

Some communities had transient populations which affected attendance. One principal highlighted the difficulty of tracking students whose parents did not advise the school of their relocation. Transport also emerged as a factor for many schools, due to families' financial circumstances. In remote communities, having to see a doctor or attend a family commitment could lead to extra time away. A few principals referred to young people who had parents in prison and how this impacted upon students:

Their attendance seems to slip ... I have a child here whose parents and brothers have been in a revolving door ... He just does not want to attend because he's not sure when they are coming or going, or police are raiding.

These principals identified issues such as domestic violence, for example: 'These kids don't want to come to school because they are scared that mum is going to get beaten up while they are here, and they see themselves as protectors'. There were also issues related to drug and alcohol abuse. One principal commented that 'I can see how great the impact of alcohol abuse is, first and foremost on our families; followed now, living in this rural area, the effects of 'Ice' and alcohol and other drugs on families'.

Principals, especially those in schools with high Indigenous populations, identified cultural issues that impacted on some families in their schools, issues which also intersected with economic and location factors. For instance, 'Sorry Business' which relates to a period of mourning for Indigenous peoples, involving particular cultural practices and protocols associated with death that affected Indigenous students' school attendance at times. For example, one principal in a regional school outlined some of the issues: 'So if it's very expensive for them, for example, to go to a funeral in the Torres Strait. They will get the money together to go there; but then they take a month to save up the money to actually return back to school'. In one rural school, the Principal noted that: 'One family is currently in [a town $600 \mathrm{~km}$ away] and they have had Sorry Business since before the holidays, because they have now had three deaths in a row in the family'.

Physical and mental health were also seen as impacting on students' capacity to attend school regularly. For example one primary school principal indicated that:

I have got a ... little preppie [5 year old] ... who really for the first six months of the year, only attended between sort of 9 and 10.30 ... because of his treatments. ... But I'm never going to get him any more than that at the moment. Maybe in two years' time, when he's kicked this cancer's butt.

Anxiety, depression, and other issues of mental health were also regarded as affecting students' abilities to attend school. For example: 'I am probably working with about five or 
six in Year 12 at the moment who are sitting in those mental health issue areas. In and out of wards'. One principal noted that while very young students were facing difficult emotional issues, 'we tend to find once the kids get older, particularly in grade 11 and 12 that one of the common reasons is depression and mental illness.'

While the importance of an engaging curriculum and pedagogy were prevalent themes within the interviews, these discussions were general, for example, references to 'quality teaching and learning'. However, a few principals were very explicit about the relationship between high quality pedagogies and curricula and students' attendance. For example, 'I think the pedagogy is really important. My theory around that is: teachers need to make their classroom activities so exciting, that the kids wouldn't want to be anywhere else.' Another stated, 'When I analyse my data, the year levels where all of the teachers are more engaging in their pedagogy have better attendance'. However, most principals did not directly link curricula and pedagogies to school attendance.

Attendance data were routinely scrutinised, with an explicit focus on set targets reflecting the Department of Education's priorities outlined in the Every Day Counts initiative (Queensland Department of Education, 2008). Individualised case management strategies were developed for students who were identified as 'chronic absentees'. Other strategies focused on ensuring that school environments were welcoming of students and issues of bullying were addressed.

\section{Strategies to improve attendance}

The principals elucidated a range of strategies that they had developed within their school communities to improve attendance. The monitoring of student attendance data was seen as essential by most principals. Principals typically monitored the data daily; students were regularly informed of their own data, usually on a weekly basis, often during assembly and in form classes at regular intervals, for example every five weeks, at the end of term, the end of each semester and/or the end of year. 'At risk' students were identified early for intervention.

Messages about attendance were explicitly and regularly conveyed to students. The importance of setting and communicating high expectations was commonly discussed by the principals in the interviews. These expectations related to attendance as well as behaviour and academic achievement. It was very apparent in these schools that everybody - teachers, students and parents - was aware of the importance of attendance. Some schools really drove home the message that achievement at school was dependent upon attending, for example, 'We directly target the fact 'if you are not in the classroom, you can't get an A'. One principal gave the following example:

So we put up all the signs 'every day counts'; we put up the graphs showing attendance; and we found that the most important thing is: when the teachers are 
seeing the progress (in attendance) being published on our school page, and we celebrate with the kids.

In some cases, students were constantly being reminded about the importance of school attendance: "We have a sign running all year about "every day counts"; and we had a big push on that. So we talk about the "every day counts" mantra; that is a big one for us.' This approach was evident in the use of 'data walls' which included visual displays of student attendance data that many of the principals linked to Sharratt and Fullan's (2012) 'Putting Faces on the Data'. In some schools these data walls were changed every day and were in every classroom. The principals regularly analysed the data asking, 'What's the data telling me? Is it particular year levels, perhaps, or classes? Is it particular days of the week?'

Most schools utilised these data to implement an intensive case management approach in order to tailor interventions to meet the needs of students who were identified as disengaged or at risk of disengaging. These students were identified through state and school level attendance data. As a principal stated, 'Every kid who is below $85 \%$ attendance, we case manage'. For example, 'We get the parents in; and then we just lay everything out on the table and say, "Look, here's the data ... and then we case manage it from there, almost individually; and try and solve their issues.'

These principals commonly described implementing 'wrap-around' case management, involving support staff and external agencies, in order to identify and 'fix' problems. They reported some success: 'that individual case management ... it's hard but we have certainly had some big wins in there', and 'we are able to get a kid from below $85 \%$ to way above, simply because we are chasing through and looking at a solution for them'. Equity issues were considered by some principals who referred to 'social justice meetings' to provide individualised support:

If it has been a traumatic situation in the family due to domestic violence or other major issues, then... we will look at some of that flexible attendance. We will support them in the playground; we will support them differently in the classroom.

In this way, case management sometimes led to modified programs or timetables which might entail a special classroom on site with a dedicated teacher and a flexible program. Some students obtained school-based apprenticeships or traineeships with community businesses or were offered alternative academic pathways.

The principals acknowledged the 'power of work' that goes on in schools, but that schools cannot succeed on their own. They reported that the schools worked collaboratively with external agencies such as youth mental health services, Police Citizens Youth Clubs and family support agencies to remove barriers to attendance. For example:

I am in the process of employing a social worker for the school ... there are all sorts of people, case managing and working with kids with attendance issues. The social worker will pull all of that together and coordinate that. 
Some schools with high Indigenous populations made a significant effort to address issues by employing an Aboriginal and/or Torres Strait Islander liaison officer to conduct home visits, and by working with local communities, especially Indigenous Elders. One urban, multicultural school had employed several staff from different ethnic backgrounds, such as Vietnamese, Somalian, Middle Eastern and Pacifika.

Most schools had a reward system to drive attendance. These rewards were diverse in nature; ranging from small prizes such as pencils and stickers, to certificates for attendance, to pizza parties, jumping castles and movie nights, to lunch with the Principal, to an iPad. One primary school had a 'picnic excursion' for those students who had reached a 'target' attendance. However, some principals expressed caution in placing too much emphasis on rewards. As one said:

I don't think it is sustainable to always have those extrinsic things ... it's superficial ... You have to look at the culture around learning and ensuring kids are confident learners, so that they feel valued at school, and that will have that deep down, this is why we need to be at school.

Some schools had also introduced extra-curricular programs to attract students. These included robotics, chess, music and sports programs, as well board games and social events.

Most schools had sanctions of some kind or other in response to significant student absenteeism. However, a view summed up by one principal was shared by many others: 'certainly those punitive actions are the least effective, I believe'. While some schools issued detentions, others questioned this approach, asking, 'Why would you come to school, if you are going to get a detention for being away?' Similarly, there was little support for suspending students for frequent absences. In many schools, especially in the senior years, the possibility of cancellation of enrolment was seen as a necessary instrument to 'jolt a child/family into action'. This view on cancellation was not universal. In some cases, the principals preferred to transition these students into alternative educational or vocational pathways.

There was very little support for legislative processes that punished parents for their children's non-attendance. For example, there was a strong view that fining parents was ineffective, and that resources would be better employed in providing support for families. Other principals noted that there were cases pending, although this was often described as a last resort, and a 'toothless tiger'. The principals were also concerned that instigating legal processes destroyed relationships with the community, affecting trust and the ability to build partnerships. One experienced principal, who had never sent out an official notice to parents under the Education (General Provisions) Act 2006, expressed concerns that parents with low levels of literacy would not be able to read or understand the form.

The most common form of sanction entailed the withholding of privileges, such as attending the senior formal, graduation, school camps, sport and end of year celebrations. For 
example, Year 12 students in one school were informed that their attendance would be linked to '... the fun things at the end of Grade 12 that they want to access.' Some principals argued that this did not technically represent a sanction, but rather they were not being rewarded. It was also argued by some principals that sanctions could be detrimental to creating a positive school climate.

Creating a positive environment was often seen as key to engaging students. This emphasis was reflected in one principal's comment: 'I would probably say it would have to be the environment and the feel of the school ... So kids are happy; they feel safe ... staff are friendly. It just has that type of environment and feeling.' Addressing bullying was considered critical to ensuring a safe as well as positive school climate.

The interviews revealed the importance of communication and building relationships with students, their parents/carers and the local community, with one principal stressing that their approach was about 'communication, communication, communication' at every level within the school. Another school leader described 'a softly, softly approach ... we have a relationships approach ... If you spoke to my staff ... they would tell you I would say the crucial thing about our school is building relationships ... everything we do is relationships; and I would say we do that well'. More specifically, relationships between parents and the school were articulated as a partnership: 'I think there needs to be an understanding that it is a partnership ... our partners within that are the system are the parents ... because that's in the majority of cases the reason why students get to school or in some cases don't get to school'. Furthermore, the following scenario highlighted the significance of these relationships and communication with families:

We had one parent who was intellectually impaired, his daughter was intellectually impaired ... the youngest child was in Grade 2; he wasn't attending ... When we rang him, he said, 'Oh, I don't send them when it's raining' ... What it came back to was: his education wasn't good, but he valued education, he didn't want his books and stuff to get wet ... So we got him an umbrella and spoke about which way they could go ... and the attendance improved.

Getting to know the students' family thus enabled a simple solution to what may have been otherwise assumed to be a complex problem.

\section{Discussion and Conclusion}

The principals in this study contribute to the debate about ways to improve attendance. They had been identified by the Queensland Department of Education as school leaders who had productively addressed chronic absenteeism in their schools through a range of strategies and initiatives. The schools were located in predominantly low SES communities across metropolitan, regional and remote areas of Queensland. What emerged from the interviews were leadership practices characterised by a planned and strategic approach that emphasised communication and aimed to create collective ownership across every level of 
the school community. There was recognition of the need for a reflective approach and the mindset that 'we can do this better'. This set of interviews indicated that this was not a short term strategy or one-off occurrence, but a sustained long-term approach. This is supported by Creighton (2007) who argues that leadership is not about being visionary, but about being tenacious and strategic. It was clear that there was a strong commitment to change, a high level of persistence and ongoing critical evaluation of strategies. Strategies for change were directed at different levels and drew on community resources available to schools to respond to social issues within the local context. This resonates with the literature which acknowledges the complexity of improving attendance and the need for strategies that address multiple and interconnected factors (Marvul, 2012; Kearney, 2008).

Attendance was part of the common discourse within the schools; with teachers, students, parents and community members made aware of the schools' attendance targets. These principals monitored attendance data closely to plan appropriate courses of action. The subsequent strategies were diverse, ranging from removing barriers to school attendance to facilitating conditions which promoted attendance. The importance of constantly refining and trying new approaches was emphasised.

Life circumstances of students that impacted on their ability to attend school, such as personal, economic, social and cultural factors were important considerations in the implementation of these strategies. The schools often put in place support structures, such as flexible timetables and learning programs, which aligns with the literature that suggests flexibility is important for improving attendance, especially for vulnerable young people (Kearney, 2008; Mills \& McGregor, 2014). They also sought to remove barriers, such as lack of food, uniforms and transport, which inhibited attendance. This connects with the idea of 'clearing the path for learning' (McGregor et al., 2017) to address the difficulties children and young people may face.

Strategies to strengthen schools' relationships with parents/carers emerged as a significant element of an overall relationships-based approach. This has been shown in the research literature as crucial to improving school attendance (Eaton et al., 2008). Attending to the school climate and relationships were intended to make school a place where students and parents/carers wanted to be. This approach is supported by research which suggests that a safe school environment and respectful relationships improves attendance (DeSocio et al., 2007; Povey et al., 2016). Principals viewed sanctions as a last resort, perceiving them to be counterproductive to positive school-parent relationships. Legal sanctions such as punitive measure have rarely been shown to be successful (Eastman, Cooney, O'Connor, \& Small, 2007; Reid, 2010). These principals were more inclined to focus on rewards and celebrations. However, some expressed the need for caution in emphasising extrinsic reinforcers as have some researchers who have argued that the use of incentives may undermine the purpose of education and school as a place of learning (Arthurs, Patterson \& Bentley, 2014). 
Another common feature of these schools was their relationships with their local communities. The principals reported that they worked collaboratively with a diverse range of external agencies to develop a tailored approach for individual students experiencing difficulties; making the point that schools cannot succeed on their own. Some schools with high Indigenous Australian and ethnic populations worked with local Elders, and employed staff from diverse ethnic backgrounds to build relationships by bridging language and cultural differences.

Loutzenheiser (2002) observes that 'The reasons that students disconnect or reconnect with schooling cannot be boiled down to a single, neat package or list of alterations' (p. 461). This was evident in the present study, with the approaches reflecting the diversity of the schools and their contexts. The complexity of issues facing the principals demanded social and cultural awareness and responsiveness. Holistic, problem-solving and pragmatic approaches were evident in the work of these principals and their school communities. These schools could be seen as going 'above and beyond' in developing workable solutions to often deep, complex and seemingly intractable problems and circumstances which impacted student attendance. It should be noted that as these schools had been purposively selected, the insights of the school leaders present a picture of what can be achieved in often challenging circumstances in one Australian state. As such, these findings may not be transferable to other contexts. These principals stressed that purposeful and meaningful curricula and engaging pedagogies are crucial to improving learning outcomes. However, in general, while quality teaching and learning practices were considered important, the relationship between curriculum, pedagogy and attendance was not explicit. Research has emphasised the importance of quality curricula and pedagogical practices to engage students and thus improve attendance (McGregor et al., 2017). The lack of this connection in the present study suggests the need for a shift from extrinsic reinforcers towards more intrinsic strategies which seek to improve attendance by enhancing student engagement through quality teaching and learning practices within a positive school environment, which is an area for future research.

\section{Acknowledgement}

The authors gratefully acknowledge the assistance of the Queensland Department of Education for their funding and ongoing support. They also wish to acknowledge the 50 principals involved in the project for their time and contributions. 


\section{References}

Arthurs, N., Patterson, J., \& Bentley, A. (2014). Achievement for Students Who are Persistently Absent: Missing School, Missing Out? Urban Review: Issues and Ideas in Public Education, 46(5), 860-876. doi: 10.1007/s11256-014-0307-4

Baxter, L. P., \& Meyers, N. M. (2016). Increasing urban Indigenous students' attendance: Mitigating the influence of poverty through community partnership. Australian Journal of Education, 60(3), 211-228. doi: 10.1177/0004944116664438

Birioukov, A. (2016). Beyond the excused/unexcused absence binary: classifying absenteeism through a voluntary/involuntary absence framework. Educational Review, 68(3), 340-357. doi: 10.1080/00131911.2015.1090400

Braun, V., \& Clarke, V. (2006). Using Thematic Analysis in Psychology. Qualitative Research in Psychology, 3(2), 77-101. doi: http://dx.doi.org/10.1191/1478088706qp063oa

Corville-Smith, J., Ryan, B., Adams, G., \& Dalicandro, T. (1998). Distinguishing absentee students from regular attenders: The combined influence of personal, family and school factors. Journal of Youth and Adolescence, 27(5), 629-640.

Creighton, T. (2005). What is leading below the surface? In Leading from below the surface: A nontraditional approach to school leadership (pp. 17 - 24). Thousand Oaks: Corwin Press.

DeSocio, J., VanCura, M., Nelson, L., Hewitt, G., Kitzman, H., \& Cole, R. (2007). Engaging Truant Adolescents: Results From a Multifaceted Intervention Pilot. Preventing School Failure: Alternative Education for Children and Youth, 51(3), 3-9. doi: 10.3200/PSFL.51.3.3-11

Dickson, E. D., \& Hutchinson, T. (2010). Truancy and the Law in Australia: The Queensland example. The International Journal of Law and Education, 15(2), 87-102.

Driver, R., \& Watson, C. (1989). Construct validity of voluntary and involuntary absenteeism. Journal of Business and Psychology, 4(1), 109-118. doi: 10.1007/BF01023041

Eastman, G., Cooney, S. M., O'Connor, C., \& Small, S. A. (2007). Finding Effective Solutions to Truancy. Wisconsin IL: University of Wisconsin, Madison.

Elliott, J. G. (1999). Practitioner Review: School Refusal: Issues of Conceptualisation, Assessment, and Treatment. J. Child Psychol. Psychiat., 40(7), 1001-1012.

Forde, C., Horgan, D., Martin, S., \& Parkes, A. (2018). Learning from Children's Voice in Schools: Experiences from Ireland.

Gase, L. N., DeFosset, A., Perry, R., \& Kuo, T. (2016). Youths' perspectives on the reasons underlying school truancy and opportunities to improve school attendance. The Qualitative Report, 21(2), 299-320.

Gillborn, D. (2008). Racism and Education: Coincidence or Conspiracy? London: Routlege.

Gottfried, M. A. (2009). Excused versus Unexcused: How Student Absences in Elementary School Affect Academic Achievement. Educational Evaluation and Policy Analysis, 31(4), 392-415.

Ham, B. (2004). The Effects of Divorce and Remarriage on the Academic Achievement of High School Seniors. Journal of Divorce \& Remarriage, 42(1-2), 159-178. doi: 10.1300/J087v42n01_08

Justman, M., \& Peyton, K. (2014). Enforcing Compulsory Schooling by Linking Welfare Payments to School Attendance: Lessons from Australia's Northern Territory Melbourne Institute Working Paper No. 19/14. Melbourne: Melbourne Institute of Applied Economic and Social Research. 
Kearney, C. (2008). An Interdisciplinary Model of School Absenteeism in Youth to Inform Professional Practice and Public Policy. Educational Psychology Review, 20(3), 257-282. doi:

10.1007/s10648-008-9078-3

Kearney, C., \& Graczyk, P. (2014). A response to intervention model to promote school attendance and decrease school absenteeism. Child and Youth Care Forum, 43(1), 1-25.

Kearney, C. A. (2003). Bridging the Gap Among Professionals Who Address Youths With School Absenteeism: Overview and Suggestions for Consensus. Professional Psychology: Research and Practice, 34(1), 57-65. doi: 10.1037/0735-7028.34.1.57

Loutzenheiser, L. W. (2002). Being Seen and Heard: Listening to Young Women in Alternative Schools. Anthropology \&amp; Education Quarterly, 33(4), 441-464. doi:

10.1525/aeq.2002.33.4.441

Marvul, J. N. (2012). If You Build It, They Will Come: A Successful Truancy Intervention Program in a Small High School. Urban Education, 47(1), 144-169. doi: 10.1177/0042085911427738

McGregor, G., \& Mills, M. (2012). Alternative Education Sites and Marginalised Young People: I Wish There Were More Schools Like This One. International Journal of Inclusive Education, 16(8), 843-862. doi: 10.1080/13603116.2010.529467

McGregor, G., Mills, M., te Riele, K., Baroutsis, A., \& Hayes, D. (2017). Re-Imagining Schooling for Education. London: Macmillan Publishers

McIntyre-Bhatty, K. (2008). Truancy and coercive consent: is there an alternative? Educational Review, 60(4), 375-390. doi: 10.1080/00131910802393407

Mills, M., \& McGregor, G. (2014). Re-engaging Young People in Education: Learning from alternative schools New York : Routledge: Abingdon, Oxon.

National School Climate Council. (2007). The School Climate Challenge: Narrowing the gap between school climate research and school climate policy, practice guidelines and teacher education policy. Retrieved from

https://www.schoolclimate.org/themes/schoolclimate/assets/pdf/policy/school-climatechallenge-web.pdf

Povey, J., Campbell, A., Willis, L., Haynes, M., Western, M., Bennett, S., Antrobus, E. \& Pedde, C. (2016). Engaging Parents in Schools and Building Parent-School Partnerships: The role of school and parent organisation leadership. International Journal of Educational Research, 79, 128-141.

Queensland Department of Education. (2008). Every Day Counts. from http://education.qld.gov.au/everydaycounts/

Raby, R. (2014). Children's participation as neo-liberal governance? Discourse: Studies in the Cultural Politics of Education, 35(1), 77-89.

Reid, K. (1999). Truancy in Schools. London: Routledge.

Reid, K. (2007). Managing school attendance: the professional perspective. Teacher Development, 11(1), 21-43. doi: 10.1080/13664530701194652

Reid, K. (2010). Finding strategic solutions to reduce truancy. Research in Education, 84(1), 1-18.

Reid, K. (2012). Reflections of being 'A man of truancy': 40 years on. Educational Studies, 38(3), 327340.

Robinson, C. (2011). Children's rights in student voice projects: where does the power lie? Education Inquiry, 2(3), 437-451. doi: 10.3402/edui.v2i3.21993 
Robinson, C., \& Taylor, C. (2013). Student Voice as a Contested Practice: Power and Participation in Two Student Voice Projects. Improving Schools, 16(1), 32-46. doi:

$10.1177 / 1365480212469713$

Rocque, M., Jennings, W. G., Piquero, A. R., Ozkan, T., \& Farrington, D. P. (2016). The Importance of School Attendance: Findings From the Cambridge Study in Delinquent Development on the Life-Course Effects of Truancy. Crime \& Delinquency. doi: 10.1177/0011128716660520

Skattebol, J., Blaxland, M., Brennan, D., Adamson, E., Purcal, C., Hill, T., ... Williams, F. (2014). Families at the Centre: What do low income families say about care and education for their young children? Sydney: Social Policy Research Centre.

Skattebol, J., \& Hayes, D. (2016). Cracking with Affect: Relationality in Young People's Movements in and out of Mainstream Schooling. Critical Studies in Education, 57(1), 6-20. doi: 10.1080/17508487.2015.1096803

Steers, R. M., \& Rhodes, S. R. (1978). Major influences on employee attendance: A process model. Journal of Applied Psychology, 63(4), 391-407. doi: 10.1037/0021-9010.63.4.391

Tate, S., \& Greatbatch, D. (2017). Alternative Provision: Effective Practice and Post 16 Transition. London.

Taylor, C., \& Robinson, C. (2009). Student Voice: Theorising Power and Participation. Pedagogy, Culture and Society, 17(2), 161-175. doi: 10.1080/14681360902934392

Van Eck, K., Johnson, S. R., Bettencourt, A., \& Lindstrom Johnson, S. (2017). How school climate relates to chronic absence: A multi-level latent profile analysis. Journal of School Psychology, 61, 89-102.

Zhang, M. (2004). Time to change the truancy laws? Compulsory education: its origin and modern dilemma. Pastoral Care in Education, 22(2), 27-33.

Zubrick, S. (2014). School Attendance: Equities and inequities in growth trajectories of academic performance. Paper presented at the ACER Research Conference, Quality and Equality: What does research tell us?, Adelaide, Australia. 